\title{
Large and ongoing outbreak of haemolytic uraemic syndrome, Germany, May 2011
}

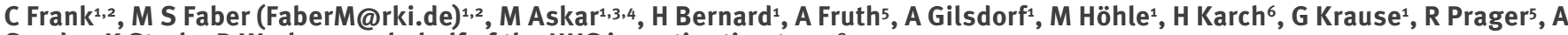
Spode $^{7}, \mathrm{~K} \mathrm{Stark}^{1}$, D Werber ${ }^{1}$, on behalf of the HUS investigation team ${ }^{8}$

1. Robert Koch Institute, Berlin, Germany

2. These authors contributed equally to the manuscript

3. Postgraduate Training for Applied Epidemiology (PAE, German Field Epidemiology Training Programme), Robert Koch Institute, Department for Infectious Disease Epidemiology, Berlin, Germany

4. European Programme for Intervention Epidemiology Training (EPIET), European Centre for Disease Prevention and Control (ECDC), Stockholm, Sweden

5. National Reference Centre for Salmonella and other bacterial enteric pathogens at the RKI, Wernigerode, Germany

6. Consulting laboratory for haemolytic uraemic syndrome, Institute of Hygiene, University of Münster, Germany

7. Local health department Hamburg Nord, Hamburg, Germany

8. The members of the team are listed at the end of the article

Citation style for this article:

Frank C, Faber MS, Askar M, Bernard H, Fruth A, Gilsdorf A, Höhle M, Karch H, Krause G, Prager R, Spode A, Stark K, Werber D, on behalf of the HUS investigation team. Large and ongoing outbreak of haemolytic uraemic syndrome, Germany, May 2011.

Euro Surveill. 2011;16(21):pii=19878. Available online: http://www.eurosurveillance.org/ViewArticle.aspx?Articleld=19878

Article published on 26 May 2011

Since early May 2011, an increased incidence of haemolytic uraemic syndrome (HUS) and bloody diarrhoea related to infections with Shiga toxin-producing Escherichia coli (STEC) has been observed in Germany, with most cases in the north of the country. Cases reported from other European countries had travelled to this area. First results of a case-control study conducted in Hamburg suggest an association between the occurrence of disease and the consumption of raw tomatoes, cucumber and leaf salad.

An unusually high number of cases of haemolytic uraemic syndrome (HUS) has been observed in Germany since early May 2011. This report presents the preliminary results of the investigation as of 26 May 2011

Haemolytic uraemic syndrome (HUS) is a serious and sometimes deadly complication that can occur in bacterial intestinal infections with Shiga toxin (syn. verotoxin)-producing Escherichia coli (STEC/VTEC). The complete clinical picture of HUS is characterised by acute renal failure, haemolytic anaemia and thrombocytopenia. Typically it is preceded by diarrhoea, often bloody. Each year, on average 1,000 symptomatic STEC-infections and approximately 60 cases of HUS are notified in Germany, affecting mostly young children under five years of age [1]. In 2010 there were two fatal HUS cases [1].

STEC are of zoonotic origin and can be transmitted directly or indirectly from animals to humans. Ruminants are considered to be the reservoir, especially cattle, sheep and goats. Transmission occurs via the faecal-oral route through contact to animals (or their faeces), by consumption of contaminated food or water, but also by direct contact from person to person (smear infection). The incubation period of STEC is between two and 10 days, the latency period between the beginning of gastrointestinal symptoms and enteropathic HUS is approximately one week.

\section{Outbreak description}

The Table lists the number of cases of HUS or suspected HUS notified to local health departments and communicated by the federal states to the Robert Koch Institute (RKI). Suspected HUS are included as the syndrome is a process and suspected HUS typically develops over the course of a few days into the full clinical picture.

Disease onset (regarding diarrhoea) in the 214 patients detected so far was between 2 and 24 May 2011. A total of 119 (56\%) of the cases were communicated from four northern federal states (Hamburg, Schleswig-Holstein, Lower Saxony and Bremen). The highest cumulative incidence has been recorded in the two northern city states of Hamburg and Bremen. An additional 31 cases occurred in Hesse. They were connected to a catering company supplying the cafeterias of a company and a residential institution. It is likely that these cases constitute a satellite outbreak.

Besides the geographic clustering, the age and sex distribution of the cases is conspicuous: Of the 214 cases, $186(87 \%)$ are 18 years of age or older (mostly young to middle-aged adults) and $146(68 \%)$ are female. In the notification data for HUS cases from 2006 to 2010, the proportion of adults lay between $1.5 \%$ and $10 \%$ annually, and the sexes were affected equally.

Cases linked to this outbreak were also communicated from other European countries: On 25 May 2011, Sweden reported through the European Warning and Response System (EWRS) nine cases of HUS, four of whom had 
travelled in a party of 30 to northern Germany from 8 to 10 May. Denmark reported four cases of STEC infection, two of them with HUS. All cases had a recent travel history to northern Germany. Another two HUS cases with travel history to northern Germany in the relevant period were communicated, one each by the Netherlands and by the United Kingdom.

So far two German HUS cases have died of the disease (both female, one in her 80s, one in her 20s).

\section{Laboratory investigations}

Investigations at the National Reference Centre for Salmonella and other bacterial enteric pathogens at the RKI (Wernigerode) of isolates from two patients from Hesse and Bremerhaven suggests that the outbreak strain is an $E$. coli strain of serotype 0104 with the following characteristics: Shiga toxin 2 (vtx2a, EQA nomenclature 2011, WHO Centre E. coli SSI Copenhagen)- producing, intimin (eae)-negative and enterohaemolysin (hly)-negative. The strain shows a high resistance to third generation cephalosporins (through extended spectrum beta-lactamases, ESBL, (TX-M-type), and a broad antimicrobial resistance to, among others, trimethoprim/sulphonamide and tetracycline.

\section{TABLE}

Cases of HUS and suspected HUS with onset of diarrhoea since 2 May 2011, Germany $(n=214)$

\begin{tabular}{|c|c|c|}
\hline Federal State & $\begin{array}{c}\text { Number of } \\
\text { HUS cases and } \\
\text { suspected-HUS } \\
\text { cases }\end{array}$ & $\begin{array}{l}\text { Cumulative } \\
\text { incidence } \\
\text { (per } 100,000 \\
\text { population) }\end{array}$ \\
\hline Hamburg & 59 & 3.33 \\
\hline Bremen & 11 & 1.66 \\
\hline Schleswig-Holstein & 21 & 0.74 \\
\hline Mecklenburg-Vorpommern & 10 & 0.61 \\
\hline Hesse & 31 & 0.51 \\
\hline Saarland & 5 & 0.49 \\
\hline Lower Saxony & 28 & 0.35 \\
\hline North Rhine-Westphalia & 31 & 0.17 \\
\hline Berlin & 3 & 0.09 \\
\hline Baden-Württemberg & 8 & 0.07 \\
\hline Bavaria & 5 & 0.04 \\
\hline Thuringia & 1 & 0.04 \\
\hline Rhineland-Palatinate & 1 & 0.02 \\
\hline Brandenburg & 0 & 0.00 \\
\hline Saxony & 0 & 0.00 \\
\hline Saxony-Anhalt & 0 & 0.00 \\
\hline Total & 214 & 0.26 \\
\hline
\end{tabular}

HUS: haemolytic uraemic syndrome.

Data as of 26 May 2011, 8am, communicated to the Robert Koch Institute by the federal states.
A further 13 isolates from Muenster, Paderborn, Hamburg and Frankfurt were analysed in the consulting laboratory for haemolytic uraemic syndrome in the Institute of Hygiene at the University hospital in Muenster. All were sequence-typed as ST678 (stx1-, stx2+, eae-, flagellin-coding gene $\mathrm{flicH}_{4}$ ), group HUSEC 41 , also indicating serotype $0_{104}[2,3]$. Whether these results reflect the entire situation in Germany needs to be confirmed by the analysis of a greater number of isolates. As in the past most outbreaks of HUS in Germany and elsewhere were found to be connected with STEC 0157 strains, the identification of serotype 0104 in this context is highly unusual, although, E. coli 0104 has previously been described as the cause of an outbreak in the United States in 1994 [4].

\section{Investigation into the source of infection}

The large number of persons suddenly affected, the geographical and demographic distribution as well as first interviews of patients suggested STEC-contaminated food as the vehicle of infection. Foods like raw milk and raw meat, which were identified as vehicles in former STEC outbreaks, appear not to be related to the current event. Preliminary results of a case-control study conducted by the RKI and the Hamburg health authorities demonstrate a significant association between disease and the consumption of raw tomatoes, cucumbers and leafy salads. This study collected food histories for the week before symptom onset for 25 patients hospitalised with HUS $(\mathrm{n}=20)$ or bloody diarrhoea with laboratory-confirmed STEC infection $(n=5)$, who all had onset of disease between 9 and 25 May 2011. In addition, 96 controls matched by age, sex and residence were asked about their food consumption during the week before the interview. The food items they were asked about were those frequently mentioned in previous in-depth interviews of HUS cases. Consumption of each of the named food items was reported by around $90 \%$ of the cases in comparison to around $60 \%$ of the controls, yielding odds ratios between around 4 and 7 , all statistically significant. Nevertheless it is possible that another or an additional food item is the source of infection. The results cannot necessarily be transferred to the whole of Germany because the study was limited to Hamburg.

Regarding the source of the suspicious food items the study showed a heterogeneous picture. It can be excluded that the source is a single shop or restaurant. Based on these findings, food trace-back investigations are currently ongoing.

\section{Evaluation of the situation}

The current events represent one of the largest described outbreaks of HUS/STEC worldwide and the largest in Germany, with a very atypical age and sex distribution of the cases. Incident cases of HUS or suspected HUS are continuing to be reported at least in Northern Germany, where the emergency room consultations for bloody diarrhoea remain elevated. Thus it has to be assumed that the source of infection is still 
active. Many patients with bloody diarrhoea need to be admitted to hospital, and HUS patients often need intensive care with dialysis and/or plasmapheresis, which puts a severe strain on hospital resources in some areas. The epidemiological studies that were conducted in cooperation with regional and local health departments rapidly delivered important clues as to certain food items that could be linked to the outbreak. Further epidemiological studies, laboratory investigations and trace back of food items is needed to confirm these results and to narrow down the source of infection.

\section{Recommendations for consumers and patients}

Considering the ongoing outbreak that included many cases with a severe course of disease, the RKI and the Federal Institute for Risk Assessment (BfR) recommend to abstain from consuming raw tomatoes, cucumbers and leafy salads, especially in northern Germany, until further notice. Regular food hygiene rules remain in effect [5].

For persons with diarrhoea the importance of strict hand hygiene is emphasised. Patients with bloody diarrhoea should seek medical aid immediately. Physicians are reminded to initiate STEC stool diagnostics for these patients and to closely monitor them for the development of HUS. Patients suspected of developing HUS should be referred to appropriate stationary care.

Diagnostic laboratories are requested to send STEC isolates to the National Reference Centre for Salmonella and other bacterial enteric pathogens. The Protection Against Infection Act of 2001 renders both the laboratory confirmation of an STEC infection and the clinical diagnosis of HUS or suspected HUS notifiable to the local health department.

\section{Acknowledgments}

We gratefully acknowledge the contribution of all local and state health departments, the Federal Institute for Risk Assessment (BfR) and all patients and healthy citizens of Hamburg who agreed to being interviewed. We would also like to thank all hospitals in Hamburg who supported the work of the field teams.

The members of the HUS investigation team were:

Karen Atzpodien, Susanne Behnke, Merle Böhmer, Udo Buchholz, Manuel Dehnert, Julia Hermes, Kerstin Krügermann, Marion Marx, Ingeborg Mücke, Mathias Nachtnebel, Janina Neifer, Stine Nielsen, Ines Noll, Kerstin Prahm, Ute Preuß, Cornelius Remschmidt, Thorsten Rieck, Bettina Rosner, Susanne Schink, Daniel Schmidt, Franziska Schwarz, Britta Schweickert, Petra Stöcker, Thorsten Süß, Bernhard Ultsch, Maria Wadl

(Robert Koch Institute, Department for Infectious Disease Epidemiology, Berlin, Germany)
Gerhard Fell (Institute for Hygiene and Environmental, Hamburg, Germany)

Johannes Dreesmann (State Health Department of Lower Saxony, Hannover, Germany)

Ulf Panzer, Sigrid Harendza (Department of Internal Medicine III, University Medical Center Hamburg-Eppendorf, Hamburg, Germany)

Jun Oh (Department of Pediatric Nephrology, Medical Center Hamburg-Eppendorf, Hamburg, Germany)

Stefan Sudmann (Department for emergency medicine, Marienkrankenhaus, Hamburg, Germany)

Ute Juers (Asklepios Klinik Barmbeck, Hamburg, Germany)

References

1. SurvStat. Berlin: Robert Koch Institute. German. Available from: http://www3.rki.de/SurvStat. [Accessed: 24 May 2011].

2. HUSEC Referenzstammsammlung. [HUSEC collection of reference strains]. Muenster: Konsiliarlabor für HämolytischUrämisches Syndrom (HUS). German. Available from: http:// www.ehec.org/index.php?lang=de\&pid=HUSEC

3. Mellmann A, Bielaszewska M, Köck R, Friedrich AW, Fruth A, Middendorf $B$, et al. Analysis of collection of hemolytic uremic syndrome-associated enterohemorrhagic Escherichia coli. Emerg Infect Dis. 2008;14(8):1287-90.

4. Centers for Disease Control and Prevention (CDC). Outbreak of acute gastroenteritis attributable to Escherichia coli serotype 0104:H21--Helena, Montana, 1994. MMWR Morb Mortal Wkly Rep. 1995;44(27):501-3.

5. Verbrauchertipps: Schutz vor Lebensmittelinfektionen im Privathaushalt. [Consumer advice: Protection from food-borne infections in the private household]. Berlin: Bundesinstitut für Risikobewertung; 2007. German. Available from: www. bfr.bund.de/cm/350/verbrauchertipps_schutz_vor_ lebensmittelinfektionen_im_privathaushalt.pdf 